\title{
The Role of Internet/YouTube in the Socialization/Popularization of Science in Brazil
}

\author{
Roberta G. Leão \\ Graduate Program of Education (PPGE) of the Federal University of Espirito Santo \\ (UFES) \\ Av. Fernando Ferrari, 514 - Goiabeiras, Vitória - ES, 29075-910, Brazil \\ E-mail: robertag.leao@gmail.com \\ Reninni Taquini \\ Graduate Program of Education (PPGE) of the Federal University of Espirito Santo \\ (UFES) \\ Av. Fernando Ferrari, 514 - Goiabeiras, Vitória - ES, 29075-910, Brazil \\ E-mail: rtaquini@gmail.com \\ Kyria R. Finardi (corresponding author) \\ Universidade Federal do Espírito Santo (UFES) \\ Av. Fernando Ferrari, 514 - Goiabeiras, Vitória - ES, 29075-910, Brazil \\ E-mail: kyria.finardi@gmail.com
}

Received: October 8, 2019 Accepted: November 24, 2019 Published: November 27, 2019

doi:10.5296/elr.v5i2.15935 URL: https://doi.org/10.5296/elr.v5i2.15935

\begin{abstract}
The study aims to analyze how science is socialized and popularized through the internet, more specifically, through the YouTube (YT) platform in Brazil. The study gives a brief presentation of the current socio-historical context in Brazil before presenting the theoretical framework that is based mainly on Michel Foucault's notion of knowledge and power, and its relations with the forms of control in society and on Theodor Adorno's view of mass culture. In order to analyze YouTube's role in the socialization/popularization of science, sixteen YT
\end{abstract}


channels were analyzed in the first semester of 2019. The method used is mixed (Dörnyei, 2007) using a predominantly quantitative approach to measure projection in the internet of the channels analyzed. Qualitative analysis focuses on issues of content and source in the videos analyzed. In general, the analysis of the results suggests that STEM areas have a higher prevalence in the description of the videos. The study concludes with the suggestion that the platform improves the search engine so that users can filter more specific areas of knowledge, thus expanding the potential of the internet and this site in the dissemination and popularization of modern science.

Keywords: YouTube, Science, Popularization and Socialization, Brazil

\section{Introduction}

Brazil is currently facing a turmoil in its political, economic and educational systems as a result of the election of right-wing President Jair Bolsonaro in 2018, despite the opposition of voters in most of the public universities in that country. As briefly outlined by Taquini, Finardi and Amorim (2017) and described in the EMI 2018 Guide (Note 1), the Brazilian higher education system is composed of private and public institutions whereby the most important difference between the two systems lies in the fact that public universities are (still) completely free of charge, depending mostly on financing from the national government. Not only students in public universities do not pay fees but also and in many cases, they are supported by academic scholarships and funds for higher education and research.

The Brazilian higher education system is different from most systems in the world not only because of the reliance on national funds (and complete gratuity for students in the case of public universities) but also, and according to Finardi and Ortiz (2015), because of the motivation to internationalize in public and private institutions. The aforementioned authors claim that unlike universities in Europe and in the USA which had an economic motivation to internationalize (with a view to raising funds in the form of fees paid by international students), Brazilian higher education institutions (HEI) differ in their motivations to internationalize. According to the aforementioned authors, while public HEI had only an academic motivation to internationalize, once they could not receive funds in the form of fees, private HEI that represent about $75 \%$ of all HEI in Brazil did not aim to internationalize, basically because the domestic "market" was very comfortable considering the population in the country (almost 210 million people) and the fact that most of this population goes to private HEI since there are not enough public HEI for all.

During a speech that aimed to announce cuts in financing for public higher education institutions made in May 2019 (Note 2), the Minister of Education, in a fiercely debated comment, justified the cuts on the grounds that most of what happened in public universities in Brazil could be described as balbúrdia, a word that in Brazilian Portuguese translates into mess, bedlam. Fueled by opposing/reaction voices spread through social networks in the internet, many academics starting posting news about the research/education/science activities that they carried out in these public HEI, giving rise to a social movement that was rightly coined as academic balbúrdia. Hashtags with balbúrdia have been created, fed and shared in the social networks and internet sites since then.

The internet, through new technologies, became essential for those who seek to be connected 
to what happens in the world in real time, to socialize, to communicate or share information and knowledge. The Middle Ages gave way to the Media Ages, with enchantments and disenchantments with mass culture (Vianna, 1992) and its limitless space-time to receive/send information. Likewise, the web 2.0, which replaced the static web 1.0, has expanded social participation on the internet by turning mere content users/recipients into online content user/producers in what Bruns (2006) coins the produsage turn.

Assuming that all inclusion generates exclusion, new technologies and particularly the internet, allow access to information to those who own the financial capital (Hobson, 1983) to acquire the devices that allow access; and also technological capital - since it demands some level of digital literacy to access them (Xavier, 2011); thus excluding those who are not included in the two groups mentioned above. Finardi, Prebianca and Momm (2013) go further to suggest that given that approximately $80 \%$ of internet content is in English, some knowledge of the language (in addition to digital literacy) is essential to be included in the benefits that internet can bring in the expansion of access to online information.

Considering the spread of knowledge in the cyberspace (e.g. Levy, 2010), this study aims to analyze channels that are self-classified as scientific dissemination channels on YouTube, regarding their range as informed in the platform itself. These channels can be classified by their creators into categories: animals, science and technology, education, entertainment, sports, movies and cartoons, humor, instructions and style, music, news and politics, people and blogs, vehicles, travel and events (Serrano \& Paiva, 2008).

Taking Bruns' (2006) notion of produsage coupled with the Web 2.0 blurring of the boundaries between users and online content producers, one can see the possibilities of the YouTube (YT) platform, launched in 2005, as the largest global video platform worldwide. YT allows "produsers" to post and watch videos besides enabling interaction about contents with other members and contents through sharing.

Nowadays, most people can participate in the imagistic production of knowledge and culture, dissolving the idea of only one holder (producer) of knowledge. The platform acts as a repository of videos that can be filtered by channel, date or number of views by users. There are comments from viewers stating that they could only understand a book or content after watching the video, regardless of whether they are posted by amateur or professional users.

In the Foucaultian assumption that knowledge is never neutral and it is always constituted through power relations (Foucault, 2003), we can assume that, in the case of internet, the same content can be explored differently by channels that defend divergent ideollogical and political positions, attracting and repulsing, at the same time, different viewers/users for the same reasons. Personal values can promote a bipolarization about what constitutes as science or "scientific knowledge" and what is not. This polarization (what science is or is not) is perceived in the contents/comments published in the internet and ultimately reflect the current political moment in Brazil with strong polarization between the right/left political orientations and views of what constitutes education/science and what it does not.

User engagement through likes, shares and comments rank videos which are spread while algorithms work to suggest contents similar to what users have watched, increasing their time on the platform. Also, this makes the video's company/author capitalize more views with 
advertisements placed according to the interest of the viewer.

The YT platform has promoted community interaction at a global scale, although the language used in the video, as warned by Finardi, Prebianca, and Momm (2013) earlier, may restrict access to those who do not master this language. As previously stated, English corresponds to most of the content published on the internet and is used as an online lingua franca. According to Finardi and Tyler (2015), some knowledge of English is required not only to access online content but also to expand the chances of accessing online education through participation in Massive Online Open Courses (or MOOCs in the abbreviation and henceforth). Finardi and Tyler (2015) analyzed MOOCs in terms of language and area and the results of their study showed that $83 \%$ of them are available in English only. Considering estimates that only $5 \%$ of Brazilians speak English, it can be concluded that this access is very limited in Brazil not only because of issues related to infrastructure and access but also because of the vehicular language chosen for the online contents.

In fact, when it comes to the role of language in the dissemination of national scientific production, Finardi and França (2016) point out that although Brazil has the 13th largest world scientific production, this production is not computed/reflected in international rankings. The aforementioned authors add that though the Brazilian scientific production is quantitatively robust, in qualitative terms, this production does not have the desired effects, among other reasons, because of the language in which it is published (Portuguese) in its greater part.

According to the 2017 census by the Brazilian Institute of Geography and Statistics, IBGE (Instituto Brasileiro de Geografia e Estatística) (Note 3), Brazil is a developing country where internet reaches three out of four dwellings in the country (74.9\%). This number, as well as cell phone possession, increases progressively, while landline telephone presence and access to information through microcomputers has been decreasing. The access is higher in the age group from 20 to 24, with 88.4\%; and among the elderly (60 years or older), 31.1\% have access to the device. This data show the trend of small, light and portable devices that meet people's immediate communication needs.

However, it is necessary to evaluate internet access not only as a broad access to devices (Warschauer, 2004), but also as critical access to literacies and knowledges that involve the use of such devices (e.g. Finardi \& Vieira, 2016). Given the scope and limit of this study, we will not be able to deepen on the critical use of YouTube for science dissemination but we would like to do add a caveat here by inviting studies in this area to broaden the reflections made here.

\section{Theoretical Framework}

According to Marconi and Lakatos (2010), scientific knowledge differs from common sense because of its systematic, verifiable and factual standards. "Science is a whole set of rational attitudes and activities directed at systematic knowledge with limited object, capable of being submitted to verification" (Ferrari, 1974, p.8 cited in Marconi; Lakatos, 2010, p. 62).

Scientific knowledge can be divided into formal (logic and mathematics) and factual (natural and social sciences) knowledge. Thus, by thinking about science videos posted on YouTube, we must consider whether there is a macro-level strategy on the platform to systematize videos into categories and subcategories; but also at the micro level, we must consider content developers, so that they disclose content with sources, based on fact rather than opinion, in an 
impartial way. However, returning to Foucault's notion that there is no such thing as "neutral knowledge", it derives from it that power has ways of controlling society (Foucault, 2003). Thus, we advocate that the internet area can be used for individuals to fight for their own autonomy, sharing information and opinions in an environment favorable to the manipulation or domination of ideas (Habermas, 1989). In this environment, individuals who have more convincing (factual or opinionated) arguments on a specific theme/topic would be more powerful, as represented by the number of followers.

The philosopher Han (2017) understands that the current society values clarity, prioritizing everything that is operational, calculable and fast, over what is narrative, detailed and time-consuming. Departing from this assumption, we can draw an analogy with the way in which the exact sciences (Science, Technology, Engineering and Mathematics - STEM areas, sometimes called "hard sciences") have had more prestige over the humanities (Arts). Evidence of this in Brazil can be found in the extinct national academic mobility program Ciência sem Fronteiras (Note 4) (Science without Borders) which offered scholarships for university students in the following courses: engineering and other technology areas; exact and earth sciences; biology, biomedical and health sciences; computing and information technologies; aerospace technology; drugs; sustainable agricultural production; oil, gas and mineral coal; renewable energies; mineral technology; biotechnology; nanotechnology and new materials; natural disaster prevention and mitigation technologies; biodiversity and bioprospecting; sea sciences; creative industry; new construction engineering technologies; and technologists training (Finardi \& Archanjo, 2018).

We notice in this type of initiative, reported in Finardi and Archanjo (2018) and many other channels in Brazil, a devaluation of the humanities, confirmed in recent funding cuts for philosophy and sociology (Note 5) courses, on the grounds that investments in higher education should focus on areas that bring immediate return to taxpayers. Moreover, considering that the Ministry of Education justified recent cuts in budgets to higher education saying that universities were making more "noise" than "science", we think this view of science must be analyzed and so as to illustrate this point with data from the internet, the present study looks at YT.

Comparing old and new technologies, it is possible to say that the former, like television programs, previously imposed and centralized their opinions through their channels to a large portion of the population, whereas the later in the form of digital media, decentralized the status of opinion makers placing everyone on a level where they send and produce information accessible to all (Han, 2018) and this is enhanced, as we mentioned earlier, by the Web 2.0.

The need for a "scientific literacy" arises as an "appropriation by people of knowledge, understanding and skill required for effective action in daily life due to the importance of the role of science, mathematics and technology in modern life" (Cazelli, Marandino \& Studart, 2003 , p. 83). Once more we see the definition of "scientific" linked to the "hard" sciences and we relate this view to the recent cuts in Brazilian higher education (Note 6) reported in the introduction of this paper, we may see how the issue of hierarchy and power is highlighted in the view of knowledge and access to it.

Matta (2006) states that most users of educational videos available online are individuals who 
want to learn in an independent and autonomous way. As such, they choose specific themes and videos to watch depending on individual criteria. Moran (2013) affirms that the digital media forces schools to think less traditionally, since knowledge is not found only within their walls.

New schools need teacher training focused on the new educational demands, since a new way of communicating emerges, namely, the digital language. So as to illustrate this change in mindset in Brazil, a museum in Rio de Janeiro (Note 7) relaunched masterpieces using hashtags in their descriptions in order to attract a generation that was born in a connected world. With the internet generation, digital resources become essential to develop shared education in a local and global level.

Some studies (e.g. Finardi \& Pimentel, 2013; Bento \& Cavalcante, 2013, etc.) address the use of online learning tools such as Whatsapp, Facebook, Duolingo, Instagram, YouTube and virtual learning environments in pedagogical practices. We can relate this trend to Adorno's studies (1995) on television, which was the newest technology of his time. Drawing an analogy with the concept of halbbildung, the internet can be considered as formative and de-formative. Although television can have an educational nature, it makes a large number of viewers spend a lot of time on entertainment programs. What sets television apart from the internet as a content discloser, is that the internet enables almost unlimited autonomy from what its users want to access, thus, enabling their emancipation.

\section{Methodology}

Following the parameters of the inductive research method (Marconi \& Lakatos, 2010), we note that the easy access to several contents through technology can lead to shallow information that does not always help decision making, but rather encourages individuals to repeat information and habits that are not always the most appropriate ones (Han, 2017).

The importance of listing the scientific dissemination channels on the online video platform, YouTube, was chosen in order to interpret the range of the vehicle of information. So as to analyze how scientific knowledge is spread on the platform, a predominantly quantitative survey of the channels that identified themselves as scientific dissemination channels was carried out. Interference from YouTube algorithms that define which videos and channels will be featured according to user habits and preferences was removed.

The descriptor "scientific dissemination" was used in the YouTube search bar with the following criteria for the selection and cut off point for the analysis: channels with more than 500 subscribers and recent activity until 2019. The survey using these criteria yielded 16 channels, which were then analyzed according to the information in their description fields, number of followers and number of views. It was possible to establish a relation between the range of these channels and the power relations that are placed in their description analyzing how this affects the quality of scientific dissemination in general.

\section{Results and Analysis}

By using the term "science dissemination channels" in YouTube's search bar in the survey of channels that were subscribed to the platform, we found that YouTube does not make it clear if there are any search filters for channels, content or country of origin. Therefore, the search results were disordered, containing simple posts on the topic and scientific dissemination 
channels. We also could not find a filter to sort out scientific dissemination channels by areas of knowledge such as the humanities, exact sciences, language, education, and so on. Thus, we selected 16 channels that met the criteria described above. These channels are listed in the table below, along with the description provided by the channel itself (translated from Portuguese) and the number of subscribers to each one of them.

Table 1. YouTube channels analyzed

\begin{tabular}{|c|c|c|c|}
\hline Channel & & Description & $\begin{array}{l}\text { Number of } \\
\text { subscribers }\end{array}$ \\
\hline $\begin{array}{l}\text { Science } \\
\text { Vlogs } \\
\text { Brasil }\end{array}$ & & $\begin{array}{l}\text { Some of the most influential and famous names in scientific } \\
\text { video dissemination in Brazil come together in an } \\
\text { unprecedented and innovative project: creating a collaborative } \\
\text { approval seal that guarantees quality, reliable and relevant } \\
\text { scientific information! This is Science Vlogs Brasil! If there is } \\
\text { our brand, you can trust that the science there is good. } \\
\text { @svbroficial \#svbroficial a) What are the criteria for obtaining } \\
\text { the SVBR seal? Having scientific dissemination production on } \\
\text { Youtube and go through the selection process b) How do I get } \\
\text { my channel to get the SVBR seal, and then become an SVBR } \\
\text { partner? 1- Become a SVBR friend. This is done through } \\
\text { contact, agreement and official interaction with one of the } \\
\text { SVBR partner channels, it is up to them to decide who your } \\
\text { SVBR friends will be 2- in an appropriate moment, the board } \\
\text { evaluates the SVBR nominated friend channel 3- a group of } \\
\text { experts from the disseminated area will make a channel } \\
\text { evaluation 4- Evaluation by the SVBR partner channel } \\
\text { community 5- Invitation to receive the seal. }\end{array}$ & 60834 \\
\hline & & $\begin{array}{l}\text { This channel has the SVBR seal, Science Vlogs Brazil, which } \\
\text { attests the quality of scientific dissemination on Youtube. Meet } \\
\text { the proposal: } \\
\text { https://www.youtube.com/channel/ucqid87j08pe5nypz-nczw } 2 \mathrm{w} \\
\text { /channels }\end{array}$ & \multirow[b]{2}{*}{18431} \\
\hline & & $\begin{array}{l}\text { Hello, human! This is a channel with videos about Science and } \\
\text { Technology. In it, among other things, you will find: Scientific } \\
\text { Dissemination with USP Professors - Quantum Computing - } \\
\text { Black Holes - Magnetic Resonance - Programming } \\
\text { Conversations - How to learn programming? - What } \\
\text { programming language should you learn first? - Mathematics } \\
\text { for Programming Scientific Dissemination of Neuroscience - } \\
\text { What is the Brain? - Mathematics, Linguistics and } \\
\text { Neuroscience - Alzheimer's Disease. Besides History of } \\
\text { Science, Python Lessons and Conversations about the Physics }\end{array}$ & \\
\hline
\end{tabular}


course.

My name is Diogo, I'm 16 years old and I have an astronomical passion for physics and the Universe. This channel is dedicated to explaining topics in mathematics, physics, astronomy, cosmology and others, venturing us from the foundation of reality to the most colossal black hole. This channel holds the SVBR seal, Science Vlogs Brasil, which attests to the quality of Portal da scientific dissemination on Youtube. Other channels with the $\begin{array}{llll}\text { Ciência } & \text { seal can be found at } & \text { be } \\ & \text { https://www.youtube.com/channel/ucqid87j08pe5nypz-nczw2w }\end{array}$ /channels?View=60 Channel Topics: Modern Physics: I explain the physics studied after 1900, such as Relativity and quantum mechanics. $\mathcal{V}$ Cosmology and Astronomy: I explain the workings of celestial bodies and the universe itself. $\boldsymbol{V}$ Others: Videos about the political, economic and social context in Brazil and the world. Hope you enjoy the videos! A hug, Diogo.

Hello Humans, I am a very old being who decided to leave the Event Horizon in Sagitarrius A*. Crossing the galaxy in search of adventure. I found this planet you call Earth that is rich in biodiversity and decided to make a stop. Unfortunately my spaceship crashed into one of the mountains in Brazil and now there is no way to go back home. However, don't worry, instead of crushing weeds, piling stones and building pyramids, I decided to adapt to the human way of life, go to astronomy Café e college and then I created this YouTube channel to talk about Ciência astronomy, space exploration and science. Your way of life is very interesting, I just do not understand why you are destroying everything... For business appointments: contato@supernova.etc.br SVBR is a seal that attests the quality of scientific dissemination on Youtube. I am a SVBR Partner, I value the good scientific dissemination and seek vigorously to strengthen the SVBR, thus fostering the diverse community of scientific disseminators on Youtube. $\mathrm{Http} / / /$ youtube.com/sciencevlogsbrasil

Our brain has developed over billions of years of evolution, reaching a complexity that gives us the ability to think on our own existence and to have a big curiosity on how the universe

Papo de works. Welcome to a channel where this skill is exercised, with Primata science-based videos that encourage the adoption of a rationalist view of the world. Meet a hominid's thoughts on life, the universe, and everything!

SVBR is a seal that attests the quality of scientific 
Minutos

Psíquicos

Primata

Falante

Canal

Ciencialize

Astrotubers

Dispersciên cia dissemination on Youtube. I am a SVBR Partner, I value the good scientific dissemination and vigorously seek to strengthen the SVBR, thus fostering the diverse community of scientific disseminators on Youtube. Http://youtube.com/sciencevlogsbrasil

Minutos Psíquicos is a channel for scientific dissemination that produces videos about psychology, neuroscience, the universe and everything! Subscribe to the channel and become a member of our supporter club by clicking on "be a member" up here to receive several exclusive benefits

Complicating what is simple. Second channel (Vlogs, Primata Jogante and others): http://bit.ly/primatafalante2 Killbit channel (movies, series, etc.): http://bit.ly/killbit support: https: //www.padrim. com/primatafalante by David Simões. ---SVBR is a seal that attests to the quality of scientific dissemination on Youtube. I am a SVBR partner, I value the good scientific dissemination and vigorously seek to strengthen the SVBR, thus fostering the diverse community of scientific disseminators on Youtube. Youtube.com/sciencevlogsbrasil

Science channel featuring: astronomy, physics, chemistry, biology and technology

In 2017, during the XLI annual meeting of the Brazilian Astronomical Society (better known as SAB - Sociedade Astronômica Brasileira), several astronomers showed interest in making a scientific dissemination with a good quality, so we came together to make a YouTube channel and this channel is ASTROTUBERS. We are undergraduate and postgradluate students of physics and astronomy from various universities in Brazil. Do you want to know more about astronomy and physics? Or even about science in general? Subscribe to our channel! ;) Do you want to be an astrotuber? Fill in the form: http://bit.ly/sejaumastrotuber Astrotubers have their content certified by the Brazilian Astronomical Society. Here is a list of the projects that hold this seal of approval: http://bit.ly/selosab. This channel holds the SVBR seal, Science Vlogs Brasil, which attests to the quality of scientific dissemination on Youtube. Here is a list of the seal-holding channels: http://bit.ly/sciencevlogsbrasil

Good afternoon everyone! We are Dispersciência, a channel in which we comment on news in the world of science and we present Brazilian researchers and their works. Because we also 26756 do good quality science in Brazil! Dispersciência is part of the Science Vlogs Brasil seal of approval, which attests to the good 
content of scientific dissemination channels. Channel Art: Gustavo Arantes https://gustavoarantes.portfoliobox.net Video Background Art: Rafaela Ramos, Cassia Costa, Watson

Open Interactivity Lab Channel for Dissemination of Scientific and Technological Knowledge of the Federal University of São Carlos (labi - UFSCAR). Labi is a partner project of the Functional Materials Development Center (CDMF - Centro de Labi Desenvolvimento de Materiais Funcionais) and is supported by UFSCAR the Foundation for Supporting Research in the State of São Paulo (FAPESP - Fundação de Amparo à Pesquisa do Estado de 9640 São Paulo) and the National Council for Scientific and Technological Development (CNPQ - Conselho Nacional de Desenvolvimento Científico e Tecnológico). The Channel presents several productions of scientific dissemination, education and culture.

Tomada

Zero

The channel minds the scientific dissemination in a light and fun way.

Channel focused on scientific dissemination. The entire Traduzindo audiovisual translation process was performed by the chanmel's Ciência author and allowed with the permission of the copyright holders, as well as their reproduction. Luiz Antônio Melo, professor of physics.

Spacetodaytv is a channel for the dissemination of astronomy in Portuguese. Topics about astronomy, astrophysics, astronautics and related fields will be discussed here, always based on the latest scientific studies. We will not bow to the cheap Spacetoday sensationalism that only degrades the image of astronomy and the sciences in general in our country. We will not get into 374873 confusion, unfounded discussions and fights to make the channel grow. Only science, astronomy in the vein!!! My other contact channels: SITE: http://www.spacetoday.com.br FACEBOOK: $\quad$ http://www.facebook.com/spacetoday TWITTER: http://twitter.com/spacetoday1

Normose is a brainstorming channel for those seeking

Normose self-knowledge. Aimed to be a channel about History, Philosophy, Scientific dissemination and drug policy. Subscribe and take a reeest!

Centro de Scientific dissemination channel of the Center for Optical and Pesquisa em Photonic Research (CEPOF - Centro de Pesquisa em Óptica e Óptica e Fotônica). CEPOF is one of 17 Research, Innovation and 
Fotônica - Dissemination Centers (CEPIDS - Centros de Pesquisa,

CEPOF Inovação e Difusão) supported by FASESP. More information: http://cepof.ifsc.usp.br/ http://cepid.fapesp.br/centro/17/

Out of the 16 channels yielded by the search, 4 were organized by specific institutions, namely: Caio na Aula, organized by the professors of the University of São Paulo (USP); Astrotubers, created by members of the Brazilian Astronomical Society (Sociedade Astronômica Brasileira - SAB); Labi UFSCAR, by the Open Laboratory of Interactivity for the Dissemination of Scientific and Technological Knowledge of the Federal University of São Carlos (Laboratório Aberto de Interatividade para Disseminação do Conhecimento Científico e Tecnológico da Universidade Federal de São Carlos), funded by Foundation for Supporting Research in the State of São Paulo (Fundação de Amparo à Pesquisa do Estado de São Paulo - FASEP) and the National Council for Scientific and Technological Development (Conselho Nacional de Desenvolvimento Científico e Tecmológico - CNPQ); and finally, the channel Centro de Pesquisa em Óptica e Fotônica, which is part of the Innovation and Diffusion Research Centers (Centros de Pesquisa Inovação e Difusão CEPIDS) and it is also supported by FASEP. The other 12 channels are organized by private sectors, whether individual or collective.

Some channels used expressions such as quality, reliable and relevant scientific information, as is the case of Science Vlogs Brasil, however, they do not present the selection criteria for choosing the topics covered for the channel nor a definition of what "science with a good quality" would be. This same channel presents itself as being the developer of the SVBR seal. The SVBR seal is a way of identifying a group that calls itself a "trusted science disseminator" because according to the information provided by the group, one of the criteria for holding the seal is that all content to be disseminated must be evaluated by experts in the field. However, there is no information on who these experts are, what their academic background is or the area and institution in which they work. The channels presented with the SVBR seal are: Dispersciência, Astrotubers, Primata Falante, Papo de Primata, Café e Ciência, Portal da Ciência e Caio na Aula, in addition to the channel which generates the seal itself, Science Vlogs Brazil, totaling 8 channels.

Regarding the number of subscribers, the channel about psychology, Minutos Psíquicos, reached a higher number of followers when compared to the channels about exact sciences, obtaining 705375 subscribers. The astronomy channel Spacetoday reached 374873 followers, Primata Falante - whose description does not highlight any specific scientific area, reached 121569 subscribers and was followed by Normose, which emphasizes history and philosophy, with 103996 followers. The channel Porta da Ciência, whose creator reports to be sixteen years old, also praises the scientific dissemination of astronomy and reached 72 273 subscribers, followed by Science Vlogs Brasil with 60 834. Café e Ciência, also directed to astronomy, reached 52 815. The channels Papo Primata and Dispersciencia, with 43651 and 26756 subscribers respectively, also did not specify their thematic area. Astrotubers, another channel about astrology, has 22830 followers, while the channel Ciencialize, which focuses on the exact and biological sciences, obtained 21.898. The channels Caio na Aula, Labi UFSCAR and the Centro de Pesquisa em Óptica e Fotônica - CEPOF had 18 431, 9640 


\section{Macrothink

and 7149 subscribers respectively. Finally, the channels Tomada Zero and Traduzindo Ciencia reached a lower record - with respective 2088 and 565 subscribers, and did not highlight any specific area of dissemination.

This leads us to think on the emphasis on the exact sciences (STEM areas), where 6 channels are described as specific to the areas of astronomy, mathematics, physics and related fields in a simple search. Only one channel is focused on psychology and neuroscience, 1 adds that, in addition to the scientific dissemination, it also serves in the areas of education and culture and only 1 mentions history and philosophy in its description. Moreover, the other 7 channels did not mind to specify the areas they address, generalizing the meaning of science.

Finally, we also selected the number of views for each channel in order to visualize its range within the platform and relate it to the number of subscribers for a broader discussion of this study as can be seen in Graph 1 below.

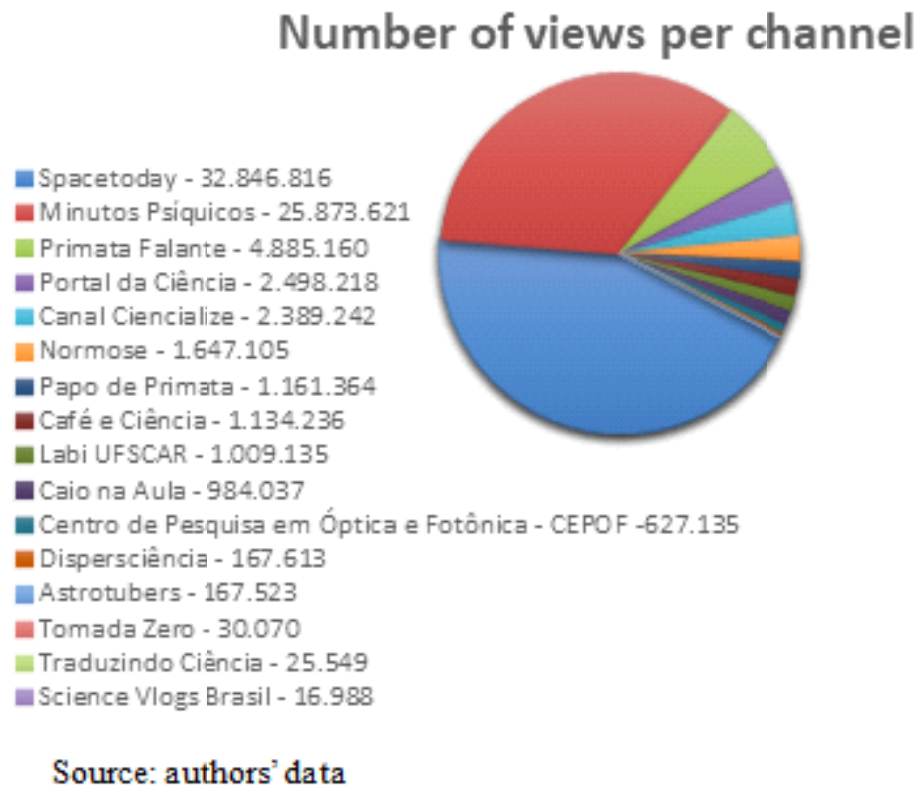

Graph 1. Number of views per channel

With 32846816 views, the most popular channel for scientific dissemination is Spacetoday, followed by Minutos Psíquicos, with 25873621 views. In this case, we can presume that the public interest in topics related to astronomy, astrophysics, astronautics and related areas is greater than their interest on psychology.

The other channels created by private sectors had the following number of views: Primata Falante, 4885 160; Portal da Ciência, 2498 218; Canal Ciencialize, 2389 242; Normose, 1 647 105; Papo Primata, 1161 364; Café e Ciência, 1134 236; Dispersciência, 167 613; Tomada Zero, 30 070; and Traduzindo Ciência, 25 549. In relation to channels linked to research institutions/groups or channels funded by funding agencies presented the following number of views: Labi UFSCAR, 1009 135; Caio na Aula, 984 037; Centro de Pesquisa em Óptica e Fotônica-CEPOF, 627 135; and Astrotubers, 167523. 
Finally, the numbers show that the channel Science Vlogs Brasil, the SVBR seal provider for other channels has the lowest number of views, a total of 16 988. Such information leads us to think on the discourse of the channel as a provider of an identification of excellence in scientific dissemination. If the site self-consideration is true, the range of the content disseminated is relatively small; and if it is false, the quality of the content disseminated by this and all other channels that consider the SVBR seal as a quality parameter can be questioned.

\section{Conclusion}

The aim of this study was to investigate how scientific knowledge is disseminated on YT. With that aim, a quantitative study was performed and through the analysis, the data suggested that YouTube still needs to improve its way of accessing scientific dissemination channels. Thematic filters would facilitate a specific analysis of channels focused on education, history, philosophy, languages, etc. However, in the absence of this feature, the platform featured several channels and videos on science as result, requiring the authors of this study to create their own analysis filter.

We observed that channels without any specification of area and channels that focus on the exact and natural sciences have a larger prevalence than those that focus on the humanities. The emphasis on the exact sciences in channel self-descriptions is a factor that favors the exact sciences on the humanities as it increases their projection on the platform. By adding the values of the visualizations and subscriptions of the exact sciences channels, this number would be significantly larger and disproportionate in relation to the channels about humanities.

The channel Minutos Psíquicos has the largest number of followers, but it is the second largest in number of views, having the opposite numbers of the channel Spacetoday. This data emphasizes even more the highlight of the exact sciences in relation to the humanities, in this case, psychology, since the only channel devoted to history and philosophy did not obtain results as expressive as the psychology channel.

When we consider data of this study in relation to the current socio-political moment in Brazil we may suggest that the YT portrays a view of science as linked to the notion of "hard sciences" whereas humanities are depicted as balburdia. As such, we can say that YT may be used to reinforce/repeat views rather than emancipate viewers with other views (of science).

Despite the relevance of channels linked to educational and research institutions or funded by external agencies, their range was not as expressive as channels carried by private sector. Again, when we see the number of private/public universities described in the introduction of this paper we may understand the "link" between science and the private sector though almost $90 \%$ of research in Brazil is made at public universities thus showing the inaccuracy of the Prime Minister of Education when describing what goes on in public universities as balbúrdia.

This result may show the need of public institutions to worry more about how they are disseminating the knowledge/science produced there, especially in non-canonic ways using, for example, social networks and the internet to increase the contents available thus legitimizing the "science" produced in these institutions and their relevance to society at 
large.

The quality of science dissemination on YouTube is a concern we consider relevant for further studies to tackle. Mainly because channels carried by private sectors have been organized with what is disclosed through the SVBR seal. However, it is still not clear how and by whom the assessment of what is disclosed in this group of channels is made. Another factor to consider is that none of this channel groups featured "soft sciences" in their description. Furthermore, none of these channels obtained such a significant range as the channels Minutos Psíquicos and Spacetoday which do not have the SVBR seal and the seal's founder channel itself got the least number of views on YouTube, making us question the essence of this "seal of approval for scientific dissemination".

\section{Acknowledgement}

The work was supported in part by the Fundação de Amparo à Pesquisa do Espírito Santo (FAPES), Brazil - Finance Code 001 (author 1).

The work was supported in part by the Coordenação de Aperfeiçoamento de Pessoal de Nivel Superior (CAPES), Brazil - Finance Code 001 (author 2).

The work was supported in part by the Fundação de Amparo à Pesquisa do Espírito Santo (FAPES), Brazil - Finance Code 001 (author 3).

\section{References}

Adorno, T. W. (1995). Educação e Emancipação. Tradução do alemão Wolfgang Leo Maar. Rio de Janeiro: Paz e Terra.

Bento, M. C., \& Cavalcante, R. S. (2013). Tecnologias móveis em educação: o uso do celular na sala de aula. Revista ECCOM, 4(7), 113-120.

Bruns, A. (2006). Towards produsage: Futures for user-led content production.

Cazelli, S., Marandino, M., \& Studart, D. (2003). Educação e comunicação em museus de ciência: aspectos históricos, pesquisa e prática. In Guaracira Gouvêa; Martha Marandino; Maria Cristina Leal. (Org.). Educação e museu: a construção social do caráter educativo dos museus de ciência (pp. 83-106). Rio de Janeiro: Acess.

Dörnyei, Z. Research methods in applied linguistics: Quantitative, qualitative, and mixed methodologies (pp. 95-123). Oxford: Oxford University Press.

Finardi, K. R., \& Archanjo, R. (2018). Washback Effects of the Science Without Borders, English Without Borders and Language Without Borders Programs in Brazilian Language Policies and Rights. In M. Siiner, F. Hult, \& T. Kupisch. (Org.). Language Policy and Language Acquisition Planning (Volume 15, pp. 173-185). Language Policy. 1st ed.Cham: Springer. https://doi.org/10.1007/978-3-319-75963-0_10

Finardi, K. R., \& Franca, C. O. (2016). Inglês na internacionalização da produção científica brasileira: evidências da subárea de linguagem e linguística. Intersecções. Revista de Estudos sobre Práticas Discursivas e Textuais, 19, 234-250.

Finardi, K., \& Pimentel, B. (2013). Crenças de professores de inglês sobre o uso do Facebook. Revista Contextos Linguisticos, 7, 238-253. 


\section{Macrothink Institute ${ }^{T M}$}

Finardi, K. R., Prebianca, G. V., \& Momm, C. F. (2013). Tecnologia na Educação: o caso da Internet e do Inglês como Linguagens de Inclusão. Cadernos do IL, 46, 193-208. https://doi.org/10.22456/2236-6385.35931

Finardi, K. R., \& Ortiz, R. A. (2015). Globalization, Internationalization and Education: What is the Connection? IJAEDU - International E-Journal of Advances in Education, 1, 18-25. https://doi.org/10.18768/ijaedu.16488

Finardi, K. R., \& Tyler, J. (2015). The role of English and technology in the internationalization of education: insights from the analysis of MOOCs. In: 7th International Conference on Education and New Learning Technologies, Barcelona. Edulearn15 Proceedings. Barcelona: IATED, 1, 11-18.

Finardi, K. R., \& Vieira, G. V. (2016). Ensino crítico de inglês e formação docente na contemporaneidade. Atos de Pesquisa em Educação (FURB), 11, 549-571. https://doi.org/10.7867/1809-0354.2016v11n2p549-571

Foucault, M. (1979). A Arqueologia do Saber. Rio de Janeiro: Edições Graal.

Foucault, M. (2003). Microfisica do Poder. (18th ed.). São Paulo: Graal.

Habermas, J. (1989). The Structural Transformation of the Public Sphere: an Inquiry to a Category of Bourgeois Society. Cambridge, MA. MIT Press.

Han, B. C. (2018). No Enxame. Petrópolis, RJ. Vozes.

Han, B. C. (2017). Sociedade da Transparência. Petrópolis, RJ. Vozes.

Hobson, J. A. (1983). A Evolução do Capitalismo Moderno. Série "Os Economistas". São Paulo Abril Cultural.

Levy, P. (2010). Cibercultura. Editora 34.

Marconi, M. A., \& Lakatos, E. A. (2010). Fundamentos de Metodologia Científica. (7th ed.). São Paulo, SP. Atlas S.A.

Matta, A. E. R. (2006). Tecnologias de Aprendizagem em Rede e Ensino de História utilizando comunidades de aprendizagem e hipercomposição. Brasília: Líber Livro Editora.

Moran, J. M. (2013). Ensino e aprendizagem inovadores com apoio de novas tecnologias. In: MORAN, José Manuel; BEHRENS, Marilda Aparecida; MASETTO, M. T. Novas tecnologias e mediação pedagógica. Campinas: Papirus.

Serrano, P. H. S. M., \& Paiva, C. C. (2008). Critérios de Categorização para os vídeos do YouTube. Revista Eletrônica Temática Insite. São Paulo, ano IV, n. 12, dez. 2008.

Taquini, R.; Finardi, K.; Amorim, G. (2017). English as a Medium of Instruction at Turkish State Universities. Education and Linguistics Research, 3(2), 35-53.

Vianna, L. C. R. (1992). A Idade Mídia: uma reflexão sobre o mito da juventude na cultura de massa. Brasília: UnB.

Xavier, A. C. (2011) Letramento Digital: Impactos das tecnologias na aprendizagem da geração Y. Revista Caleidoscopio. 9(1), 3-14. https://doi.org/10.4013/cld.2011.91.01

Warschauer, M. (2004) Of digital divides and social multipliers: Combining language and technology for human development. Analytical Survey, 46.

Van der Geer, J., Hanraads, J. A. J., \& Lupton R. A. (2000). The art of writing a scientific 


\section{Macrothink

article. Journal of Scientific Communications, 163, 51-59

\section{Copyright Disclaimer}

Copyright reserved by the author(s).

This article is an open-access article distributed under the terms and conditions of the Creative Commons Attribution license (http://creativecommons.org/licenses/by/3.0/). 